\title{
THE FUTURE OF INDUSTRIAL STATISTICS
}

\author{
DOUGLAS C. MONTGOMERY \\ Arizona State University \\ Tempe, AZ 85287-5906 USA \\ doug.montgomery@asu.edu
}

\begin{abstract}
The field of industrial statistics traces its origins from the early part of the previous century. The last 20 years have seen significant advances in both applications of the tools of industrial statistics and in the development of new methodology. The use of statistics in industry, including applications in new product design and development, optimization, and control of manufacturing processes, and in service industries continues to expand at a rapid rate. Consequently, the field of industrial statistics has emerged as an important branch of modern statistical science. These growing applications of statistics in industry have created opportunities and needs for methodological research, and many new challenges have arisen. This paper identifies some areas in which statisticians may contribute to the methodology of industrial statistics and discusses some of the educational and implementation challenges that we confront today.
\end{abstract}

\section{INTRODUCTION}

Much of the progress in statistical science in the last century came about because statisticians addressed real problems. Many of these problems were from industry, the chemical and physical sciences, and engineering. For example, Walter Shewhart developed control charts from his interaction with Western Electric personnel grappling with the problems of manufacturing telephone equipment, George Box developed response surface methodology from his work with chemists and chemical engineers, and John Tukey developed exploratory data analysis from his work with telecommunications engineers. The last 20 years has seen the field that we call industrial statistics mature into a strong and active specialty of statistical science. Several academic programs are focused at least in part on industrial statistics and graduates of these programs are finding employment opportunities in a variety of industrial and business settings. Research in industrial statistics is perhaps at all-time high, if one uses 
the number of journal articles published in the area as a criterion, and the fact that several new journals that focus primarily on industrial statistics have appeared.

As applications of statistics in industry have expanded, many new research avenues have opened. Some of these problems present opportunities for statisticians to contribute to the solutions of real industrial problems while simultaneously advancing the frontiers of statistical science. This paper summarizes some research opportunities and challenges for modern industrial statisticians and offers some on the present state of the field.

\section{A BRIEF HISTORICAL PERSPECTIVE ON INDUSTRIAL STATISTICS}

The origins of modern industrial statistics are in the early 1900s. Table 1 [adapted from Montgomery $(2001 \mathrm{a}, \mathrm{b})]$ is a summary of some of the milestone events.

An early key event in the development of industrial statistics was the establishment of a quality control department at AT\&T in the 1920s, and the pioneering ideas that emanated from that group, including Shewhart's development of the control chart and Dodge and Romig's work on acceptance sampling. Within a few years statistical quality control methods were in widespread use at Western Electric, the British textile and woolens industry was using statistically designed experiments for product and process development, and other individuals including B. P. Dudding and L. H. C. Tippett were actively involved in industrial applications of statistics.

World War II saw a greatly expanded use of statistical methods in manufacturing industries. Wartime experience made it apparent that statistical methods could play an important role in controlling and improving quality. The U. S. War Department established educational programs in statistical quality for industrial personnel.

Table 1. Some Milestones in Industrial Statistics

\begin{tabular}{|l|l|}
\hline Year & \multicolumn{1}{c|}{ Event } \\
\hline Early 1900s & First standards laboratory established in Great Britain \\
\cline { 2 - 2 } & $\begin{array}{l}\text { W.S. Gosset introduces the } t \text { distribution, based in part } \\
\text { on his work on quality control }\end{array}$ \\
\cline { 2 - 2 } & $\begin{array}{l}\text { AT\&T begins systematic inspection and testing of } \\
\text { products }\end{array}$ \\
\cline { 2 - 2 } & $\begin{array}{l}\text { British government begins a supplier certification } \\
\text { program during WW I }\end{array}$ \\
\hline
\end{tabular}




\begin{tabular}{|c|c|}
\hline & $\begin{array}{l}\text { Technical Inspection Association if formed in Great } \\
\text { Britain, later becomes the Institute of Quality } \\
\text { Assurance }\end{array}$ \\
\hline \multirow[t]{5}{*}{$1920 \mathrm{~s}$} & AT\&T forms a quality control department \\
\hline & $\begin{array}{l}\text { B. P. Dudding uses statistical methods at General } \\
\text { Electric (England) to monitor the quality of electric } \\
\text { lamps }\end{array}$ \\
\hline & W. A. Shewhart introduces the control chart \\
\hline & $\begin{array}{l}\text { Acceptance sampling methodology is developed and } \\
\text { refined by Dodge and Romig at Bell Labs }\end{array}$ \\
\hline & $\begin{array}{l}\text { Fisher publishes fundamental series of papers on } \\
\text { designed experiments, focusing on the agricultural } \\
\text { sciences }\end{array}$ \\
\hline \multirow[t]{4}{*}{$1930 \mathrm{~s}$} & $\begin{array}{l}\text { Shewhart publishes Economic Control of Quality of } \\
\text { Manufactured Product; gives lectures on statistical } \\
\text { methods in production at the University of London }\end{array}$ \\
\hline & $\begin{array}{l}\text { British textile and woolens industry begins use of } \\
\text { designed experiments for product/process } \\
\text { development }\end{array}$ \\
\hline & $\begin{array}{l}\text { RSS forms the Industrial \& Agricultural Research } \\
\text { Section }\end{array}$ \\
\hline & $\begin{array}{l}\text { W. E. Deming invites Shewhart to present lectures on } \\
\text { control charts at the U. S. Department of Agriculture } \\
\text { Graduate School }\end{array}$ \\
\hline \multirow[t]{6}{*}{$1940 \mathrm{~s}$} & $\begin{array}{l}\text { U. S. War Department publishes guide on using } \\
\text { control charts, training courses are given in industry }\end{array}$ \\
\hline & $\begin{array}{l}\text { Statistical Techniques Research group at Columbia } \\
\text { University makes many important contributions to } \\
\text { industrial statistics }\end{array}$ \\
\hline & $\begin{array}{l}\text { Bell Labs develops the forerunners of the MIL STD } \\
\text { sampling plans }\end{array}$ \\
\hline & Industrial Quality Control begins publication \\
\hline & The ASQC and the JUSE are formed \\
\hline & $\begin{array}{l}\text { Deming is invited to Japan by the Economic and } \\
\text { Scientific Services Division of the U. S. War } \\
\text { Department, gives lectures on statistical methods to } \\
\text { Japanese industry }\end{array}$ \\
\hline \multirow[t]{6}{*}{$1950 \mathrm{~s}$} & $\begin{array}{l}\text { Deming begins education of Japanese industrial } \\
\text { managers, JUSE establishes the Deming Prize }\end{array}$ \\
\hline & $\begin{array}{l}\text { Classic texts on statistical quality control by Eugene } \\
\text { Grant and A. J. Duncan appear }\end{array}$ \\
\hline & $\begin{array}{l}\text { Box and Wilson publish fundamental paper on } \\
\text { industrial experimentation, introduce response surface } \\
\text { methodology }\end{array}$ \\
\hline & $\begin{array}{l}\text { J. E. Juran invited to Japan, lectures on quality } \\
\text { management and improvement }\end{array}$ \\
\hline & Cusum and EWMA control charts introduced \\
\hline & $\begin{array}{l}\text { Technometrics is established; J. S. Hunter is founding } \\
\text { editor }\end{array}$ \\
\hline
\end{tabular}




\begin{tabular}{|c|c|}
\hline & $\begin{array}{l}\text { Quality Control Handbook by Juran and Gryna first } \\
\text { appears }\end{array}$ \\
\hline \multirow[t]{5}{*}{ 1960s } & $\begin{array}{l}\text { U. S. manned spaceflight program focuses industry on } \\
\text { reliability engineering concepts }\end{array}$ \\
\hline & $\begin{array}{l}\text { Courses in statistical quality control become } \\
\text { widespread in Industrial Engineering academic } \\
\text { programs }\end{array}$ \\
\hline & $\begin{array}{l}\text { Zero Defects, Value Engineering programs begin in } \\
\text { many industries }\end{array}$ \\
\hline & $\begin{array}{l}\text { Industrial Quality Control ceases publication, } \\
\text { replaced by Quality Progress and the Journal of } \\
\text { Quality Technology (L. S. Nelson is the founding } \\
\text { editor of JOT) }\end{array}$ \\
\hline & Quality circles introduced in Japan by K. Ishikawa \\
\hline \multirow[t]{4}{*}{ 1970s } & $\begin{array}{l}\text { British Quality Association is formed as the merger of } \\
\text { other societies }\end{array}$ \\
\hline & $\begin{array}{l}\text { Interest in quality circles grows in North America, } \\
\text { leads to the TQM movement }\end{array}$ \\
\hline & $\begin{array}{l}\text { Books on designed experiments oriented towards } \\
\text { engineers and scientists begin to appear }\end{array}$ \\
\hline & $\begin{array}{l}\text { Interest in statistical education for engineers grows, } \\
\text { some programs require these courses for all graduates }\end{array}$ \\
\hline \multirow[t]{7}{*}{$1980 \mathrm{~s}$} & $\begin{array}{l}\text { Statistical methods are introduced to a wider group of } \\
\text { industries as interest in quality improvement } \\
\text { accelerates, driven by economic and competitive } \\
\text { forces }\end{array}$ \\
\hline & $\begin{array}{l}\text { The ASA establishes the Ad Hoc Committee on } \\
\text { Quality \& Productivity, this later grows into a full } \\
\text { section of the ASA }\end{array}$ \\
\hline & $\begin{array}{l}\text { The Malcolm Baldrige National Quality Award is } \\
\text { established by the U. S. Congress }\end{array}$ \\
\hline & $\begin{array}{l}\text { The journals Quality Engineering and Quality \& } \\
\text { Reliability Engineering International appear }\end{array}$ \\
\hline & $\begin{array}{l}\text { Taguchi's work on robust parameter design appear in } \\
\text { the West, Ford Motor Company and others attempt to } \\
\text { drive these methods into their supplier base }\end{array}$ \\
\hline & Motorola's six-sigma initiative begins \\
\hline & TQM activities flourish \\
\hline \multirow[t]{4}{*}{$\begin{array}{l}1990 s- \\
2000\end{array}$} & $\begin{array}{l}\text { ISO } 9000 \text { and other standards activities increase } \\
\text { greatly, applicants for the Baldrige Award grow } \\
\text { steadily, many states sponsor quality awards based on } \\
\text { the Baldrige criteria }\end{array}$ \\
\hline & $\begin{array}{l}\text { Many undergraduate engineering programs require } \\
\text { basic education on statistical techniques, including } \\
\text { control charts and designed experiments }\end{array}$ \\
\hline & The six-sigma approach spreads to other industries \\
\hline & $\begin{array}{l}\text { ASQC becomes ASQ, attempting to indicate the } \\
\text { broader aspects of the quality improvement field }\end{array}$ \\
\hline
\end{tabular}


In July, 1942 an intensive 10-day course was given at Stanford University to industrial representatives and War Department procurement agency personnel. Many other similar courses followed. Some of the attendees of these courses were university faculty members who attended to prepare themselves to offer courses on statistical quality control at their institutions. This led to widespread education in these techniques at the university level after the war. The Statistical Techniques Research Group at Columbia University made many important contributions to industrial statistics, including Wald's development of sequential testing. The American Society for Quality Control was formed in 1946, as a merger of several regional autonomous quality societies. The journal Industrial Quality Control began publication in 1944. For many years, this was one of the principal outlets for new methods and applications of industrial statistics.

There were many important developments in industrial statistics during the 1950s and 1960s. As noted previously, the introduction of response surface methodology [Box and Wilson (1951)] was fundamental. This framework for industrial experimentation, involving both factor screening and optimization, had significant impact on the chemical and process industries and spurred much of the research in designed experiments for the next 30 years. Both the cumulative sum and the exponential weighted moving average control charts were developed and introduced during the 1950s. Reliability engineering grew initially from the manned space flight program in the United States, as well as the development of missile systems, high-performance aircraft, and orbital satellite technology. This era also saw the first "management" systems designed to promote quality, reliability, and productivity, zero defects, and value engineering. The journal Technometrics, a joint publication of the American Statistical Association and the American Society for Quality Control, was established in 1959. In 1968, Industrial Quality Control ceased publication and was replaced by two new journals, Quality Progress and the Journal of Quality Technology.

While many new technical methods were developed in the 30 years following the end of World War II, industrial deployment of statistical methods was fairly limited. Many organizations actually abandoned statistical techniques and procedures that they had used with considerable success during the war. The reasons for this are not completely known, but probably the lack of competition, the post-war economic expansion, and a lack of appreciation by scientists, engineers, and managers of the broad power of statistical methods to improve product and process design and development were contributing factors. 
In North America, competitive pressures renewed industrial interest in quality improvement in the late 1970s and early 1980s, and with this came expanded awareness of and use of statistical techniques in industry. Taguchi's work on robust parameter design was introduced in the West in this period, and Ford Motor Company and other organizations attempted to drive these methods into their supplier base. Taguchi's methodology sparked much discussion and controversy. By the late 1980s there was substantial evidence that while Taguchi's engineering concepts and objectives were well-founded, there were problems with his experimental strategy and methods of data analysis. For the specific details of these issues, see Box (1988), Box, Bisgaard and Fung (1988), Hunter (1985) (1989), Pignatiello and Ramberg (1992), Myers and Montgomery (1995), Montgomery (1999) (2001c) and the panel discussion edited by Nair et al. (1992).

There were two positive outcomes of the Taguchi controversy. First, designed experiments became more widely used in industries that had previously made little use of the technique. Second, there was renewed interest in statistical design by both researchers and practitioners, including the development of alternatives to Taguchi's technical methods that allowed his engineering concepts to be carried into practice efficiently and effectively. See Myers (1991), Myers, Khuri and Vining (1992), Lucas (1994), Myers and Montgomery (1995), and Montgomery (1999) for discussion of this methodology and examples.

In 1984, the American Statistical Association established the Ad Hoc Committee on Quality \& Productivity, which later grew into a full section of the ASA. In 1988, the U. S. Congress established the Malcolm Baldrige National Quality Award. Applicants for this award have grown steadily, and by the mid-1990s, many states had established quality awards based on the Baldrige criteria. The journals Quality Engineering and Quality \& Reliability Engineering International appeared in 1989 and 1987, respectively, providing additional outlets for the expanding research in industrial statistics. During the late 1980s Motorola's six-sigma initiative began. Within ten years, six-sigma concepts spread to many other industries. The 1990s also saw widespread interest in quality certification and standards activity. During this decade, the ASQC became the American Society for Quality. The name change was intended to reflect the broad use of quality improvement tools beyond the traditional manufacturing environment. 


\section{SOME RESEARCH OPPORTUNITIES IN INDUSTRIAL STATISTICS}

Statistical quality control has been called one of the great technological innovations of the $20^{\text {th }}$ century. It can be widely applied and it is extremely effective, at least in part because the underlying theory is simple and the basic methods are straightforward. However, as pointed out in the recent panel discussion on statistical process monitoring and control [Montgomery and Woodall (1997)], there are few areas in statistics where the gap between methodological development and application is so wide. In many industrial settings, the only technique employed for process monitoring is the original Shewhart control chart. This is disturbing, because it means that many industrial organizations have not benefited from the very useful technical advances in these methods that have occurred over the last 50 years. Woodall (2000) points out that there are many controversies among experts in this field and a number of contradictions in the recommendations for good practice. These contradictions and controversies are partly responsible for this situation.

Typically, control charts are applied to complex or high-value-add processes, as these represent the greatest opportunity for improvement in many industries. When a control chart signals, the analyst must determine which parameters of the monitored process has changed and characterize the assignable cause. Pinpointing the time at which the assignable cause has occurred is usually an essential part of these activities. This is the problem of determining a changepoint, for which there is a substantial literature [see Basseville and Nikiforov (1993)]; however, little of this work has found its way into process monitoring applications. Bayesian methods, time series modeling and analysis techniques, expert systems, and stochastic calculus are techniques that may be useful in this area. For more background and a number of useful references, see Lai (1995), Stoumbos (1999), and Yashchin (1997).

Control charts are usually applied in a monitoring mode, and adjustments are made to the process only after an assignable cause is isolated. Over time, this sequence of monitoring, diagnosis, and correction activities will reduce process variability. The control chart arose in the discrete parts industry and its statistical framework is hypothesis testing. An alternative approach that has enjoyed great success in the chemical and process industries is engineering process control (EPC). In a typical EPC system, the process output is observed and based on the current deviation of the output deviation from a desired target, an adjustment is made to a manipulatible input variable that is designed to bring the output closer to target in subsequent periods. Popular EPC schemes include integral control and proportional-integral control. 


\section{http://orion.journals.ac.za/}

EPC requires (1) a model relating the manipulatible input variables to the output, (2) the ability to forecast the output, and (3) capability to make adjustments quickly and easily. The statistical basis of EPC is parameter estimation, and it essentially operates by transferring variability in the output variable to the manipulatible input variable. Thus assignable causes are not directly identified and removed, but are adjusted out. There has been some work integrating these two approaches to reducing process variability, [see Box and Luceño (1997), Tsung, F., Shi, J., and Wu, C. F. J. (1999), and Keats et al (2000), for example], but there are many opportunities for innovative research in this area.

A primary goal for industry is the reduction of lead time, defined as the time between conception of a new product or service and its delivery to the customer. This goal is driven both by competitive forces and the pressure to reduce overall costs. The rapid evolution of technology is also a factor. There are two primary enablers that can significantly impact lead time, information and computer technology, and statistical design of experiments (DOX). In product and process design the information technology and computer tools include computeraided design (CAD) and computer-aided engineering (CAE) techniques such as finite element analysis models, electrical circuit design packages, and tool or factory level planning models for evaluating scheduling, capacity planning, and supply-chain integration and management issues. Response surface design, modeling, and optimization techniques play a very significant role in the use of these computer-aided design tools. Many of the uses of these methods thus far have been applications of existing techniques. There is a significant need to develop experimental design and analysis techniques explicitly aimed at the computer experiment environment, which can be characterized by a very large number of factors, a mixture of variables that are controllable by the designer and variables that range from difficult to control to uncontrollable, and numerous output response variables.

The design and analysis of deterministic computer experiments is different in some respects from the usual types of experiments presented in standard DOX courses. First, statistical inference (tests and confidence intervals) isn't generally appropriate because the observed response isn't a random variable. That is, the system model is

$$
y=f\left(x_{1}, x_{2}, \cdots, x_{k}\right)
$$

and not 


$$
y=f\left(x_{1}, x_{2}, \cdots, x_{k}\right)+\varepsilon
$$

where $\varepsilon$ is the usual random error component. Often the experimenter wants to find a model that passes very near (or even exactly through!) each sample point generated, and the sample points cover a very broad range of the inputs. In other words, the possibility of fitting an empirical model (low-order polynomial) that works well in a region of interest is ignored. Many types of fitting functions have been suggested. Barton (1992) gives a nice review.

If a complex metamodel is to be fit, then the design must usually have a fairly large number of points, and the designs dominated by boundary points that we typically use with low-order polynomial are not going to be satisfactory. Space-filling designs are often suggested as appropriate designs for deterministic computer models. The Latin hypercube is an example of a space-filling design. For more information on computer experiments and Latin hypercube designs, see Donohue (1994), McKay, Beckman and Conover (1979), Welch and Yu (1990), Morris (1991), Sacks, Welch and Mitchell (1989), Stein, M. L. (1987), Owen (1994) and Pebesma and Heuvelink (1999). There are many important research opportunities in this area.

Designing products and processes so that they are robust to variables that are difficult or impossible to control continues to be an important application area in industry for DOX. Response surface methods offer a modern, efficient, and highly effective approach to these problems. Furthermore, simple, highly effective implementations of these procedures are now available in widely used experimental design software. There is an education mission here to ensure that these newer and highly effective approaches to robust design and process robustness studies are more fully integrated into engineering and statistical practice. However, there are also significant research issues, including the use of more effective modeling and analysis techniques based on the generalized linear model, the integration of process/process robustness methods into computer experiments, and the development of more efficient experimental design strategies for product/process robustness studies. Myers (1999) gives an excellent overview of the current status and future direction for research in response surface methodology.

Many of our research opportunities will be driven by the complex and highly diverse set of conditions in which modern manufacturing processes operate. The industrial environment of 
today is often data-rich and highly automated. For example, in a modern semiconductor fabrication facility, each wafer may pass through several hundred processing steps, and at each step numerous measurements are typically made, sometimes on individual die features. Several thousand wafers may pass through this facility weekly. This leads to a large database consisting of millions of records on hundreds of process variables and product characteristics. In these environments there is a significant need to be able to both detect and diagnose patterns, changes, and problems in process performance. Furthermore, because of the rate of production and the economic consequences, this all needs to be done in real time, not the usual two-stage approach involving real-time detection and off-line diagnosis. This clearly involves the integration of statistical research with other fields, including engineering, information and computer technology, and knowledge-based systems. Capturing information about a complex manufacturing process and combining statistical analysis of the in-process data with information about the process technology, sequence of product flow, and engineering knowledge can allow rapid and efficient diagnosis of assignable causes of unwanted process variability. This is an area with a broad collection of research problems for statisticians, spanning multivariate statistics, special statistics, statistical computing, statistical graphics, nonparametric methods, time series analysis, and many other technical specialties.

\section{SOME IMPLICATIONS FOR STATISTICAL EDUCATION}

Because the use of statistical methods has expanded in the last 20 years, many universities now offer courses in statistical topics and methodology directed towards industrial applications. I would like to offer a few comments about the implications that industrial needs and trends have for the content of these courses.

Many statistical quality control courses are out of date. Some of the common failings of these courses include teaching that the Shewhart control chart (including individual and moving range charts) is the answer to everything, failure to thoroughly explain rational subgrouping, inadequate discussion of the impact of non-normality and autocorrelation in process data on control charts, failure to discuss various process models and the performance of control charts, and lack of effective integration of statistical process monitoring techniques with feedback adjustment and engineering process control. The education we offer both in universities and in industrial short courses and workshops needs to be enhanced and in some cases upgraded. 
For example, simple multivariate methods need to be introduced in statistical quality control courses. As noted previously, the real world in which many applications of statistical process monitoring and control take place is extremely data-rich. Monitoring a complex multivariate process with a series of univariate control charts can result in situations where an assignable cause will not be detected on any of the individual control charts. Because many "natural" variables are used to describe a process, yet the "motion" in the process is actually in a subspace of these original variables, techniques such as principal components analysis and partial least squares often are a logical basis to consider for process monitoring.

There is an analogy from designed experiments that applies to these situations: using many univariate control charts in a multivariate process is equivalent to using a one-factor-at-a-time experiment. We certainly wouldn't recommend one-factor-at-a-time experiments, and in many instances, we shouldn't routinely recommend univariate control charts. Many multivariate techniques have promise, including multivariate generalizations of standard control charts, CART, and latent structure methods, yet they're probably not used enough in practice. It is even more regrettable that most SPC courses do not encourage use of multivariate methods or even illustrate the potential value of these techniques. See MacGregor (1997) and Montgomery (1998) for more discussion.

Another important consideration in control chart usage is the type of variability exhibited by the process. Figure 1 presents data from three processes. Figure 1a and $1 \mathrm{~b}$ illustrate stationary behavior. Shewhart defined an in-control process as one for which the behavior was predictable. Clearly both of these processes satisfy this definition. The data in Figure 1a is uncorrelated, and the in-control state is described nicely by the Shewhart model

$$
x_{t}=\mu+\varepsilon_{t}
$$

where $\varepsilon_{t}$ is $\operatorname{NID}\left(0, \sigma^{2}\right)$. Conventional control charts are most effective when the Shewhart model describes the in-control state, because control chart performance can be characterized and designed so that both its false alarm rate and its ability to detect shifts are reasonable. The data in Figure $1 \mathrm{~b}$ is correlated. Such process data often occurs in the process industries, often in situations where the sampling rate is small relative to the process time constant. A plausible model for the data in Figure $1 \mathrm{~b}$ is the first-order autoregressive model

$$
x_{t}=\xi+\phi x_{t-1}+\varepsilon_{t}
$$



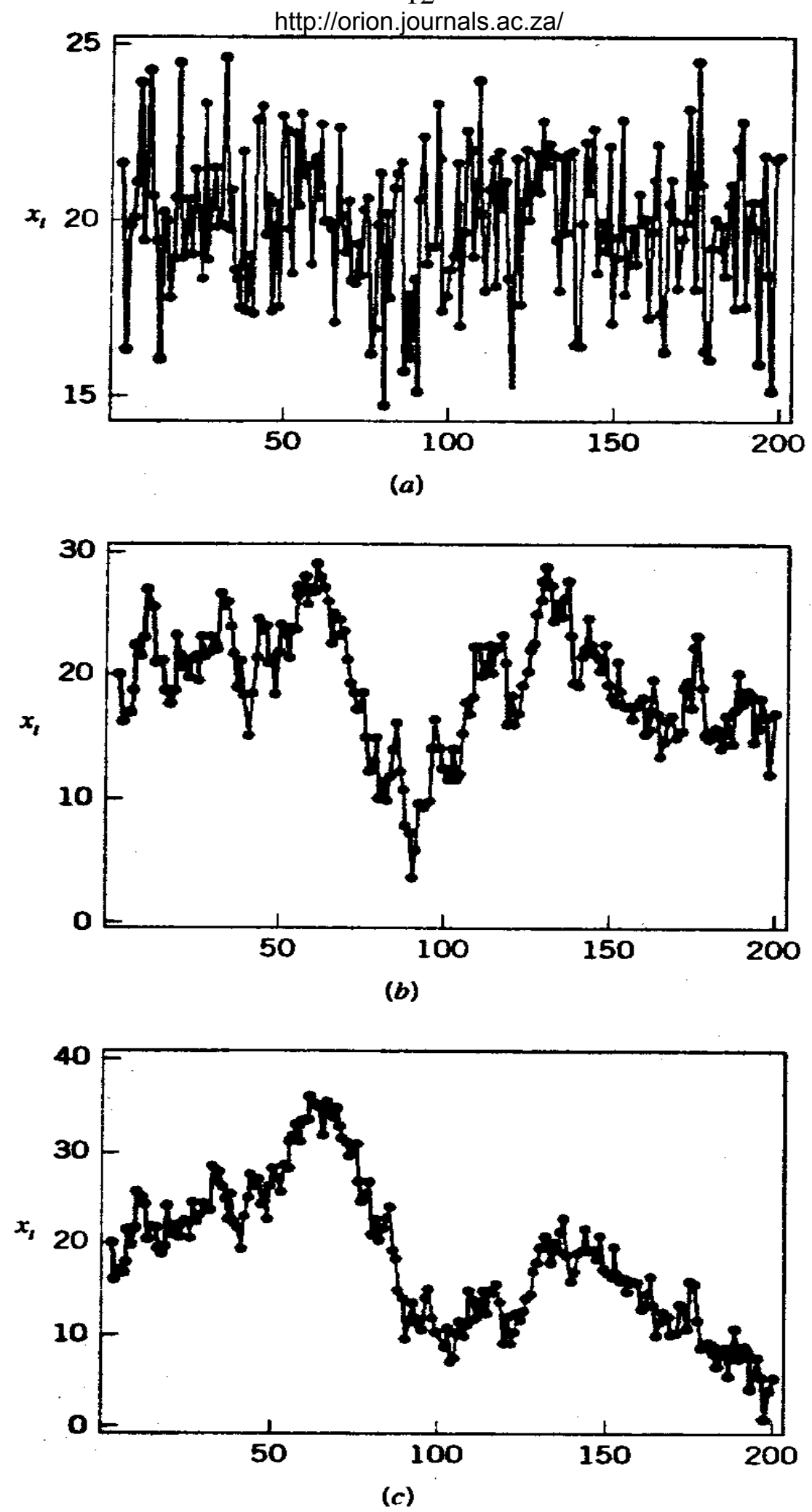

Figure 1. Data from three processes. (a) Stationary and uncorrelated. (b) Stationary and autocorrelated. (c) Nonstationary. 
Conventional control charts often do not work well in such situations, yet this situation is rarely discussed in statistical quality control courses. Figure 1c illustrates nonstationary process behavior. This type of process behavior often occurs in the chemical and process industries. A simple model that often works well in these cases is

$$
x_{t}=x_{t-1}+\varepsilon_{t}-\theta \varepsilon_{t-1},
$$

the first-order integrated moving average model. In many industrial settings we deal with nonstationary behavior by using engineering process control (such as feedback control). This approach is required when there are factors that affect the process that cannot be stabilized, such as environmental variables or raw material properties. However, few statistical quality control courses mention feedback adjust and engineering process control, or the logical interface between these techniques.

Designed experiments have penetrated many areas of industry - resulting in many new applications. Often these applications involve non-normal responses, multiple responses, and irregular regions of interest requiring non-standard designs. Experimental design courses need to introduce techniques for handling these problems, and to present modern methods for design evaluation so that an experimenter can effectively select a design that suits the situation. These design evaluation techniques need to be more effectively integrated into computer software that support designed experiments.

Methods for reliability improvement are of increasing importance. This is usually driven by reduced design/development lead-time requirements, as well as customer expectations concerning the reliability, availability, and maintainability aspects of products. The reliability of software and process equipment (predictive maintenance) are also major considerations in some industries. Very few statistics programs provide education on reliability topics, and when they do, it is usually focused on life testing and survival analysis, not the broader design aspects of the subject. It would be extremely useful for statistics programs to jointly develop a reliability course with one or more engineering departments, and for statistics and engineering faculty to teach this course jointly.

There are many other changes in statistical education that would have broad impact on the practice of statistics in industry. I suggest (1) less emphasis on measure theory and probability, (2) greater emphasis on computing skills including computer graphics and software packages linked to business management and operations systems (not just statistical 
software), (3) broader as opposed to deeper treatment of statistical theory, (4) stress discipline knowledge (e.g., engineering, science, business) in a specialized area of interest in contrast to more mathematics, (5) greater emphasis on skills such as problem identification and formulation, communication skills, and organizational aspects of business and industry, and (6) broader exposure to operations research methodology, including mathematical optimization techniques, queuing theory and scheduling, stochastic models, and forecasting/time series analysis techniques.

The value of statistical education is enhanced greatly when it is coupled with in-depth knowledge of a subject matter field. This implies that much of the future education in industrial statistics (indeed, perhaps many other areas of statistical application as well) should be interdisciplinary in nature. Curricula should be designed so that students can obtain dual majors in engineering/science/business and statistics. Certificate programs are also a way to enhance the cross-disciplinary nature of statistics, and they are probably an easier starting point than joint or dual degrees

\section{SOME CHALLENGES}

The role of the modern industrial statistician has been changing. In the decades from 19501980s, the industrial statistician was frequently the only source of statistical expertise in the organization. The role of the statistician was primarily that of a consultant, interacting with scientists and engineers mostly on technical matters. Today, many of these scientists and engineers and even some management personnel have statistical knowledge and skills, acquired in their university education or through adult professional education programs. The modern industrial statistician is often serving as a facilitator or an active team member, instead of just a consultant. He or she may be expected to provide leadership to the team (or in some cases the entire organization) on the use of statistics. This requires a different and expanded set of skills such as project management, financial analysis and general management principles. These topics are typically not part of formal statistical education or statistical consulting courses.

In many high-technology organizations the statistician is not viewed as a full team member in product and process design and development work. Furthermore, statisticians are not typically included in patent awards and design/development team recognition, and statisticians don't lead yield enhancement activities. One cause of this is that many statisticians lack the background in hard science and engineering to make content contributions to industrial development projects; consequently, they may be regarded as little more than "data 
technicians". This should provide additional impetus for statistics programs to encourage students to take more advanced courses in physics, chemistry and the engineering sciences (such as thermal and electrical science, fluid mechanics, materials science, and so forth) as electives possibly replacing courses in mathematics, and to consider forming joint degree programs with these departments. Statistics programs should also actively recruit students from engineering and the sciences and not just from mathematics. Possibly statistics faculty should hold joint appointments in an engineering, science or management department.

Often the industrial statistician is viewed as a "manufacturing" person. While there are certainly many important applications of statistics in the manufacturing setting, we must broaden this perspective into other key aspects of the business, such as information systems, supply chain management, research and development, and the "business" side of the business - accounting, finance, product marketing and distribution, for examples. Again, this points to the need for broader educational experiences for statistics students.

Certification and registration activities based on ISO 9000 (and in North America the QS 9000 standard developed by the Automotive Industry Action Group) have increased dramatically in recent years. The primary focus of these standards seems to be an attempt to document the existence of a quality assurance process without requiring any real evidence to ensure that quality improvement has actually occurred and is ongoing. In other words, the focus of these standards is only on the assurance aspects of quality, and not on the broader aspects of a quality system, which must include quality improvement and quality planning. Furthermore, the statistical components requirements are extremely weak, and suggest or require the use of poor methods, such as the process potential ratios $P_{p}$ and $P_{p k}$.

It is quite possible to be ISO/QS certified and to operate tools and processes that produce high rates of scrap and nonconforming product, and to ship this material to customers, just so long as the paperwork system documents the activity, and the corrective action. There usually isn't any follow-up to ensure that the corrective action was really effective. The auditors, registrars, consultants typically have "modest" statistical backgrounds, and a typical certification audit focuses almost exclusively on paperwork and bookkeeping.

Industrial organizations annually spend hundreds of millions of dollars on ISO and related standards certification activities, usually at the insistence of the organizations' customers. Most of this primarily enriches the standards registrars and consultants, and very little if any can be demonstrated to flow to the bottom line of the business. There is a lack of evidence 
that ISO certification has resulted in reduced variability, higher yields, safer and more reliable products, or better "quality". Indeed, during the last 18 months there have been many news stories describing rollover accidents involving Ford Explorer vehicles equipped with Bridgestone/Firestone tires. Over 100 deaths have been attributed to these accidents. This has led to a recall of approximately 6.5 million tires. Apparently many of the tires involved were manufactured at the Bridgestone/Firestone Decatur, Illinois plant. The September 18 2000 issue of Time magazine features a story on this problem showing a photograph (p.38) of the sign at the entrance of the Decatur plant. The sign includes the proclamation "QS 9000 Certified" and "ISO 14001 Certified". In the National Automobile Dealers' Association online newsletter in mid-January 2001, Ford CEO Jacques Nasser said that quality problems in new and redesigned vehicles had cost the company $\$ 1$ billion in lost profits and damaged plans for growth. While the assignable causes underlying these incidents have not been fully discovered, there is a clear and strong signal that a quality certification system that focuses only on the assurance side of quality systems is inadequate and ineffectual, and means little in terms of the actual delivered quality of products.

Industrial statisticians need to take a more active role in ensuring that quality system certification activities have a meaningful statistical component, that they have a strong focus on quality planning and quality improvement activities, and that real quality improvement is continuously occurring. Furthermore, auditors, consultants and registrars should have to demonstrate actual statistical competency. Often, too many of these individuals are knowledgeable primarily about auditing and quality assurance activities, and are unable to provide any real assessment of the effectiveness of the entire quality system or the quality and/or reliability of the products actually being manufactured.

The real tragedy of ISO/QS is that organizations have only so many resources that they can spend on quality system activities. Because a company is forced via ISO/QS to devote huge amounts of these resources to quality assurance, few if any resources are typically left to devote to quality planning and quality improvement. These are the components of the quality system where real changes in the products and services provided by the organization can occur. Reliance on ISO/QS certification alone to deliver reliable, safe and defect-free, high quality products to customers simply will not work. 
Six-sigma initiatives have become the latest framework for implementing variability reduction and quality improvement. See Hahn et al (1999) for a good discussion of the impact of sixsigma. Much of the evidence supplied by organizations that have invested in the six-sigma approach indicates that it has been very successful, leading to improvements that have impacted financial performance by hundreds of millions of dollars. I believe that there are several reasons for this success, including the widespread training in statistical methods and other problem-solving skills, and the project completion requirement, where the project has to have measurable and verifiable financial results.

While there are many aspects of the six-sigma initiative that I find appealing, other aspects of the program cause some concern. I strongly believe that widespread education in industrial statistics will pay long-run dividends. However, I believe that much of the training provided in the typical six-sigma "black-belt" courses is too technique-oriented. Furthermore, because of a supply and demand issue, individuals with limited background and experience often deliver the training. This tends to produce people that "don't know what they don't know". Such training may produce some short-term results. Even the most basic of statistics skills will often allow an individual to obtain quick results because in most organizations prior application of statistical tools has been very limited, and as a result there is a lot of "lowhanging-fruit" on the tree. However, it is a long-term mistake to over rely entirely on training-based programs such as Six-sigma to provide the main source of statistical expertise in the organization. There are many industrial problems that require considerable professional statistical expertise and a solid base of engineering or scientific knowledge to solve. The typical six-sigma "black-belt" is not necessarily adequately equipped to solve these problems.

I am a strong advocate of professional certification and accreditation. In the engineering field in North America, academic programs are accredited by the Accreditation Board on Engineering and Technology, an independent authority not involved in delivering the education, and the professional registration examination is designed and administered by the National Society of Professional Engineers, another independent authority not involved in delivering education or accrediting the academic programs. I think an independently designed and administered certification/accreditation program for six-sigma black-belts would help ensure that graduates have mastered an appropriate body of methodology. Recall that Deming was vigorously opposed to relying on slogans and programs. Remember the fate of some of the other failed initiatives such as, "value engineering", "zero defects", "TQM", and "quality 
is free"? These programs failed, often because they became little more than company-wide training programs that were assumed to be successful when a certain percentage of all employees were "trained". There was no emphasis on obtaining results and no accountability, either to or from senior management. Six-sigma probably has a better overall chance of success than these programs, because at least it's based on some of the right fundamentals, it requires a project-based implementation, and at least at the moment it seems to have management involvement and commitment in organizations where it has proven successful. However, the industrial statistics community needs to capitalize on the awareness and statistical thinking that Six-Sigma has created, and we need to seek out a broader leadership role in our organizations. CONCLUSION

During the last two decades, industrial statistics has become an increasingly important field. The $21^{\text {st }}$ century holds tremendous opportunity for statisticians, and especially industrial statisticians. However, the impact that we have on industry depends to a large extent to how well we can integrate statistical methodology with engineering and computer methodology, and how aggressive we are in modernizing our educational programs to take advantage of the opportunities. This includes modernizing education in statistical quality control, design of experiments, and reliability engineering, as well as educating statisticians more broadly in the sciences and engineering, and encouraging more interaction between statistics faculty and science, engineering and business faculty. Industrial statisticians must also find approaches to gain more input on the statistical components of certification and registration activities and to effectively support current industrial initiatives such as six-sigma. The research opportunities are also diverse and challenging, spanning many areas of statistical specialization. However, many of them will require interdisciplinary knowledge and perspective to successfully pursue.

\section{REFERENCES}

[1] R.R. BARTON, "Metamodels for Simulation Input-Output Relations", Proceedings of the Winter Simulation Conference, 289-299 (1992).

[2] M. BASSEVILLE and I.V. NIKIFOROV, Detection of Abrupt Changes: Theory and Applications, Prentice-Hall, Inc., Englewood Cliffs, NJ (1993).

[3] G.E.P. BOX, "Signal-to-Noise Ratios, Performance Criteria, and Transformations" (with discussion), Technometrics, 30, 1-40 (1988).

[4] G.E.P. BOX and A. LUCEÑO, Statistical Control by Monitoring and Feedback Adjustment, John Wiley \& Sons, New York (1997). 
[5] G.E.P. BOX and K.B. WILSON, On the Experimental Attainment of Optimum Conditions, Journal of the Royal Statistical Society, Series B, 13, 1-45 (1951).

[6] G.E.P. BOX, S. BISGAARD and C.A. FUNG, An Explanation and Critique of Taguchi's Contributions to Quality Engineering, Quality and Reliability Engineering International, 4, 123-131 (1988).

[7] J.M. DONOHUE, Experimental Designs for Simulation, Proceedings of the Winter Simulation Conference, 200-206 (1994).

[8] G J HAHN, W J HILL, R L HOERL, and S.A. ZINKGRAF, The Impact of Six-Sigma Improvement - A Glimpse Into the Future of Statistics, The American Statistician, 53, No. 3, 208-215 (1999).

[9] J.S. HUNTER, Statistical Design Applied to Product Design, Journal of Quality Technology, 17, 210-221 (1985).

[10] J.S. HUNTER, Let's All Beware the Latin Square, Quality Engineering, 1, 453-465 (1989).

[11] J.B. KEATS, M. YATSKIEVITCH, W.S. MESSINA, and D.C. MONTGOMERY, Integrating Statistical Process Monitoring with Feedforward Control, Quality and Reliability Engineering International, 16, (6), 515-525 (2000).

[12] T.L. LAI,. Sequential Changepoint Detection in Quality Control and Dynamical Systems (with discussion), Journal of the Royal Statistical Society B, 57, 613-658 (1995).

[13] J.M. LUCAS, How to Achieve a Robust Process Using Response Surface Methodology, Journal of Quality Technology, 26, 248-260 (1994).

[14] J.F. MACGREGOR, Using On-Line Process Data to Improve Quality: Challenges for Statisticians, W. J. Youden Memorial Address reprinted in the International Statistical Review, 65, 309-323 (1997).

[15] M.D. MCKAY, R.J. BECKMAN, and W.J. CONOVER, A Comparison of Three Methods for Selecting Values of Input Variables in the Analysis of Output from a Computer Code, Technometrics, 21, 239-245 (1979).

[16] D.C. MONTGOMERY, A Perspective on Models and the Quality Sciences: Some Challenges and Future Directions, W. J. Youden Memorial Address presented at the $42^{\text {nd }}$ Annual Fall Technical Conference, Corning, New York. Available in electronic form from the author (1998).

[17] D.C. MONTGOMERY, Experimental Design for Product and Process Design and Development, Journal of the Royal Statistical Society D (The Statistician), 48, Part 2, 159-177 (1999).

[18] D.C. MONTGOMERY, Introduction to Statistical Quality Control, $4^{\text {th }}$ edition, John Wiley \& Sons, New York (2001a).

[19] D.C. MONTGOMERY, Opportunities and Challenges for Industrial Statisticians, Journal of Applied Statistics, 28, No. 3, 427-439 (2001b). 
[20] D.C. MONTGOMERY, Design and Analysis of Experiments, $5^{\text {th }}$ edition, John Wiley \& Sons, Inc., New York (2001c).

[21] D.C. MONTGOMERY, and W.H. WOODALL, A Discussion of Statistically-Based Process Monitoring and Control, Journal of Quality Technology, 29, 121-162 (1997) (Eds).

[22] M.D. MORRIS, Factorial Sampling Plans for Preliminary Computer Experiments, Technometrics, 33, 161-174 (1991).

[23] R.H. MYERS, Response Surface Methodology in Quality Improvement, Communications in Statistics - Theory and Methods, 20, 457-476 (1991).

[24] R.H. MYERS, Response Surface Methodology - Current Status and Future Directions (with discussion), Journal of Quality Technology, 31, 30-44 (1999).

[25] R.H. MYERS, and D.C. MONTGOMERY, Response Surface Methodology: Process and Product Optimization Using Designed Experiments, John Wiley \& Sons, Inc., New York (1995).

[26] R.H. MYERS, A.I. KHURI, and G.G. VINING, Response Surface Alternatives to the Taguchi Robust Parameter Design Approach, The American Statistician, 46, 131-139 (1992).

[27] V.N. NAIR, et al. (Editors), Taguchi's Parameter Design: A Panel Discussion, Technometrics, 34, 127-161 (1992).

[28] A.B. OWEN, Controlling Correlations in Latin Hypercube Sampling, Journal of the American Statistical Association, 89, 1517-1522 (1994).

[29] E.J. PEBESMA, and G.B.M. HEUVELINK, Latin Hypercube Sampling of Gaussian Random Fields, Technometrics, 41, 303-312 (1999).

[30] J.J. PIGNATIELLO Jr. and J.S. RAMBERG, Top Ten triumphs and Tragedies of Genichi Taguchi, Quality Engineering, 4, 211-225 (1992).

[31] J. SACKS, W.J. WELCH, T.J. MITCHELL and H.P. WYNN, Design and Analysis of Computer Experiments, Statistical Science, 4, 409-435 (1989).

[32] M.L. STEIN, Large Sample Properties of Simulations using Latin Hypercube Sampling, Technometrics, 29, 143-151 (1987).

[33] Z.G. STOUMBOS, The Detection and Estimation of the Change Point in a Discrete Stochastic System, Stochastic Analysis and Applications, 17, 637-649 (1999).

[34] F. TSUNG, J. SHI and C.F.J. WU, Joint Monitoring of PID-Controlled Processes, Journal of Quality Technology, 31, 275-285 (1999).

[35] W.J. WELCH, and T.K. YU, Computer Experiments for Quality Control by Parameter Design Journal of Quality Technology, 22, 15-22 (1990). 
http://orion.journals.ac.za/

[36] W.H. WOODALL, Controversies and Contradictions in Statistical Process Control (with discussion), Journal of Quality Technology, 31, 376-386 (2000).

[37] W.H. WOODALL and D.C. MONTGOMERY, Research Issues and Ideas in Statistical Process Control, Journal of Quality Technology, 32, 341-378 (1999).

[38] E. YASHCHIN, Change-Point Models in Industrial Applications, Nonlinear Analysis, 30, 3997-4006 (1997). 